Resectron

\title{
Distinct pathways of cholesterol biosynthesis impact on insulin secretion
}

\author{
Juan P Zúñiga-Hertz ${ }^{1,2}$, Eduardo Rebelato', Adam Kassan ${ }^{2}$, Abdelrahman M Khalifa ${ }^{3}$, \\ Sameh S Ali ${ }^{2,3}$, Hemal H Patel ${ }^{2}$ and Fernando Abdulkader ${ }^{1}$ \\ ${ }^{1}$ Department of Physiology and Biophysics, Institute of Biomedical Sciences, University of São Paulo, \\ Av. Prof. Lineu Prestes 1524, 05508-000 São Paulo, Brazil \\ ${ }^{2}$ Department of Anesthesiology, VA San Diego Healthcare System and University of California-San Diego, \\ VASDHS (9125), 3350 La Jolla Village Drive, San Diego, California 92161, USA \\ ${ }^{3}$ Helmy Institute for Medical Sciences, Center for Aging and Associated Diseases, Zewail City of Sciences and \\ Technology, Giza, Egypt
}

Correspondence should be addressed to J P Zúñiga-Hertz Email

jpzuniga@icb.usp.br

\begin{abstract}
Results from previous investigations have indicated that glucose-stimulated insulin secretion (GSIS) is affected by changes in cholesterol and its intermediates, but the precise link between secretion and cholesterol has not been thoroughly investigated. In this study, we show the contribution of both protein isoprenylation and cholesterol-dependent plasma membrane structural integrity to insulin secretion in INS-1E cells and mouse islets. Acute ( $2 \mathrm{~h}$ ) inhibition of hydroxyl-methylglutaryl-CoA reductase by simvastatin (SIM) resulted in inhibition of GSIS without reduction in total cellular cholesterol content. This effect was prevented by cell loading with the isoprenyl molecule geranylgeranyl pyrophosphate. Chronic ( $24 \mathrm{~h})$ inhibition of cholesterol biosynthesis resulted in inhibition of GSIS with a significant reduction in total cellular cholesterol content, which was also observed after the inhibition of cholesterol biosynthesis downstream of isoprenoid formation. Electron paramagnetic resonance analyses of INS-1E cells showed that the SIM-induced reduction in cholesterol increased plasma membrane fluidity. Thus, the blockade of cholesterol biosynthesis resulted in the reduction of availability of isoprenoids, followed by a reduction in the total cholesterol content associated with an increase in plasma membrane fluidity. Herein, we show the different contributions of cholesterol biosynthesis to GSIS, and propose that isoprenoid molecules and cholesterol-dependent signaling are dual regulators of proper $\beta$-cell function.
\end{abstract}

Key Words

- secretion

- cholesterol

- isoprenylation

- membrane

\section{Introduction}

Insulin secretion in pancreatic $\beta$-cells is coupled with changes in the extracellular glucose concentration, as glucose uptake and metabolism lead to an increase in the intracellular ATP:ADP ratio. This results in an electrical response that depolarizes the plasma membrane by closure of $\mathrm{K}_{\mathrm{ATP}}$ channels, increasing intracellular calcium via voltage-dependent calcium channels leading to exocytosis of insulin granules (Henquin 2000). Despite this clear stimulus-secretion mechanism, many biochemical processes and molecules may influence its efficiency, including products of cholesterol biosynthesis. The ratelimiting step in the cholesterol biosynthesis pathway is catalyzed by hydroxymethylglutaryl-CoA (HMGCoA) reductase, which is inhibited by statins. Downstream of 
this step, isoprenoid intermediates are formed which are involved in post-translational modifications of several proteins that participate in secretory pathways. Protein isoprenylation corresponds to the incorporation of hydrophobic isoprenoid molecules such as farnesyl pyrophosphate (C15) or geranylgeranyl pyrophosphate (GGPP) (C20) into the protein structure. The mobilization of insulin granules and their fusion to the plasma membrane is markedly dependent on a family of proteins that require isoprenylation, the small GTPases (e.g., Rap1, Rac1, and Cdc42). These are involved in vesicle docking, cytoskeletal remodeling, and granule priming and fusion (Li et al. 2004, Fukuda 2005, Pechlivanis \& Kuhlmann 2006, Kowluru 2008, Wang \& Thurmond 2009, Goalstone et al. 2010).

In addition, independent of its intermediates, cholesterol itself may influence secretion. In neurons, fusion of granules with the plasma membrane is dependent on the cholesterol content of membranes, as the inhibition of cholesterol biosynthesis downstream of farnesyl synthesis impaired exocytosis of synaptic vesicles (Linetti et al. 2010). The plasma membranes of animals are enriched with cholesterol (the cholesterol:phospholipid molar ratio is 1:1) (van Meer et al. 2008). Cholesterol is not randomly embedded in membranes, but it forms microdomains such as lipid rafts. These aggregates confer order to the fluid mosaic (Singer \& Nicolson 1972, Pike 2003) and thus to membrane protein localization, determining their function in several processes, such as signal transduction (Parpal et al. 2001) and exocytosis (Linetti et al. 2010).

Conflicting evidence exists regarding the role of cholesterol in insulin secretion. An increase in insulin secretion was observed after depletion of cholesterol (by methyl- $\beta$-cyclodextrin (M $\beta C D)$ ) in the HIT-15 $\beta$-cell-line (Xia et al. 2004). On the other hand, insulin secretion was reduced in mouse pancreatic islets after inhibition of cholesterol biosynthesis downstream of farnesyl synthesis (Xia et al. 2008). Moreover, depletion of cholesterol by $\mathrm{M} \beta \mathrm{CD}$ has been also shown to reduce insulin secretion in mouse islets (Vikman et al. 2009). Interestingly, high levels of cholesterol may also influence insulin secretion. $\beta$-cells lacking the ABCA1 cholesterol transporter show increased cholesterol contents associated with reduced glucosestimulated insulin secretion (GSIS; Kruit et al. 2011).

In this study, we investigate the implication of cholesterol synthesis in $\beta$-cell function, and define the importance of isoprenoid molecules and membrane structure in GSIS. In this work, using inhibitors of cholesterol biosynthesis targeted to different key enzymes, we show the sequential effects of isoprenoids and cholesterol membrane structure on the insulin secretion process.

\section{Materials and methods}

\section{Cell culture}

The INS-1E cells (passages 53-60) were kindly provided by Prof. Pierre Maechler (Université de Genève) (Merglen et al. 2004) and cultivated in RPMI-1640 medium (Gibco) containing $11 \mathrm{mM}$ glucose and supplemented with $10 \%$ $\mathrm{v} / \mathrm{v}$ fetal bovine serum (Gibco), $100 \mathrm{U} / \mathrm{ml}$ penicillin, $100 \mu \mathrm{g} / \mathrm{ml}$ streptomycin, and $50 \mu \mathrm{M}$ 2-mercaptoethanol at $37^{\circ} \mathrm{C}$ in a humidified atmosphere of $5 \% \mathrm{CO}_{2}$.

\section{Mouse pancreatic islet isolation}

Adult mice (6 months, $25 \mathrm{~g}$ ) were used for isolation of pancreatic islets (Lacy \& Kostianovsky 1967). After animals were killed, islets were isolated by digestion with type IV collagenase (Sigma-Aldrich) $(0.68 \mathrm{mg} / \mathrm{ml})$ in Hanks' buffer (in $\mathrm{mM}, \mathrm{NaCl} 136, \mathrm{KCl} 5.36, \mathrm{MgSO}_{4} .7 \mathrm{H}_{2} \mathrm{O} 0.81$, $\mathrm{NaHPO}_{4} .12 \mathrm{H}_{2} \mathrm{O} 0.3, \mathrm{KH}_{2} \mathrm{PO}_{4} 0.44, \mathrm{CaCl}_{2} .2 \mathrm{H}_{2} \mathrm{O}$ 1.26, $\mathrm{NaHCO}_{3}$ 4.17, $\mathrm{pH}$ 7.4). The islets were maintained in RPMI medium for $24 \mathrm{~h}$ before drug treatments. All animal procedures were approved by the Animal Experimentation Committee of the Institute of Biomedical Sciences, University of São Paulo, São Paulo, Brazil.

\section{Drug treatments}

The INS-1E cells were cultured in the absence or presence of simvastatin (SIM, 0.01 or $1 \mu \mathrm{M}$, an inhibitor of HMGCoA reductase) or zaragozic acid (ZGA, 0.5 or $20 \mu \mathrm{M}$, an inhibitor of squalene synthase, thus inhibiting synthesis of cholesterol downstream of farnesyl pyrophosphate formation, without affecting the synthesis of isoprenyl molecules), in acute $(2 \mathrm{~h}$ ) and chronic $(24 \mathrm{~h})$ treatments. The chronic effect of cholesterol inhibition in primary cells was evaluated in NMRI mouse islets treated with ZGA $(20 \mu \mathrm{M})$ for 24 or $48 \mathrm{~h}$. To evaluate the influence of isoprenylation on GSIS, both INS-1E cells and C57BL/6 mouse islets were treated with $10 \mu \mathrm{M}$ of type 1 geranylgeranyl transferase inhibitor (GGTi) for $2 \mathrm{~h}$ or were loaded for $24 \mathrm{~h}$ with GGPP $(20 \mu \mathrm{M})$ before a 2 -h $\operatorname{SIM}(1 \mu \mathrm{M})$ challenge. $\mathrm{M} \beta \mathrm{CD}(1 \mathrm{mM})$ incubated for $1 \mathrm{~h}$ was used as a control for cellular cholesterol depletion. All drugs were obtained from Sigma-Aldrich and used to supplement the culture media.

\section{Insulin secretion assay}

The INS-1E cells $\left(4 \times 10^{5}\right)$ cultured in 24 -well plates were treated as described previously. The cell culture medium

Published by Bioscientifica Ltd 
was discarded and cells were washed with Krebs-Henseleit (KH) buffer (concentrations in mM: $\mathrm{NaCl} 115, \mathrm{NaHCO}_{3} 24$, $\mathrm{KCl} 5, \mathrm{MgCl}_{2} 1, \mathrm{CaCl}_{2}$ 1, pH 7.4). The cells were preincubated in $\mathrm{KH}$ buffer at $37^{\circ} \mathrm{C}$ without glucose for $2 \mathrm{~h}$. Finally, the glucose-deprived cells were incubated for $2 \mathrm{~h}$ in $\mathrm{KH}$ buffer supplemented with BSA $0.2 \% \mathrm{w} / \mathrm{v}$ and 2.8 or $16.7 \mathrm{mM}$ glucose. After retrieval of the secreted insulin in the supernatant, total cell insulin was extracted using an ethanol-water- $\mathrm{HCl}$ solution (52:17:1 v/v). Insulin concentrations in the supernatant and in the cell extracts were assayed by RIA. To carry out the insulin secretion assay in mouse pancreatic islets, the same protocol was used with a few modifications. Briefly, five islets were isolated for each test condition in triplicates. Afterwards islets were maintained for $30 \mathrm{~min}$ in KH buffer supplemented with $5.6 \mathrm{mM}$ glucose, at $37^{\circ} \mathrm{C}$ before low- $(2.8 \mathrm{mM})$ and high-glucose $(16.7 \mathrm{mM})$ stimuli. After $1 \mathrm{~h}$ of glucose stimulation, the supernatant was retrieved and the total insulin of the islets was extracted using an ethanol-water- $\mathrm{HCl}$ solution $(52: 17: 1 \mathrm{v} / \mathrm{v})$. Insulin concentrations were assayed as described previously. Insulin secretion results are presented as percentages of total islet insulin content.

\section{Cellular cholesterol content assay}

The INS-1E cells $\left(10 \times 10^{6}\right)$ were washed twice with ice-cold PBS and centrifuged for $5 \mathrm{~min}$ at $1500 \mathrm{~g}$. The cell pellet was re-suspended in $350 \mu$ l of methanol and $700 \mu$ l of chloroform. After the addition of $200 \mu$ l distilled de-ionized water, the tube was centrifuged for $5 \mathrm{~min}$ at $10621 \mathrm{~g}$. The organic phase was recovered and the solvent was evaporated over $45 \mathrm{~min}$ at $40^{\circ} \mathrm{C}$ in a Speedvac. The pellet was then dissolved in $50 \mu \mathrm{l}$ of ethanol at $37^{\circ} \mathrm{C}$ with $10 \mathrm{~min}$ shaking. The cholesterol content was quantified with a colorimetric assay (Bioclin Colesterol Monoreagente K083, Belo Horizonte, MG, Brazil). The samples were read at $500 \mathrm{~nm}$.

\section{Cell viability assay}

The INS-1E cells $\left(4 \times 10^{5}\right.$ control and SIM-treated cells up to $24 \mathrm{~h}$ ) were re-suspended in $500 \mu \mathrm{l}$ of viability buffer (propidium iodide $5.9 \mu \mathrm{M}$, Triton X-100 0.01\%, dissolved in PBS) and incubated for $30 \mathrm{~min}$ at room temperature. The viability was analyzed by flow cytometry on a Millipore Guava easyCyte 8HT flow cytometer (Millipore Billerica, MA, USA).

\section{Lipid raft fluorescence staining}

The INS-1E cells were cultured on round coverslips. GM1 ganglioside-rich membrane clusters, which correlate with total lipid raft area (van Zanten et al. 2010), were stained with the kit Vybrant Alexa Fluor Lipid Raft Labeling Kit (Invitrogen). This method is based on the specific binding of cholera-B toxin to GM1 gangliosides that mostly reside in lipid rafts, thus allowing the observation of lipid rafts clusters. Images were acquired using a fluorescence microscope (Carl Zeiss Axio Observer Z1, Jena, Germany) with $40 \times$ lens and analyzed using ImageJ Software (Wayne Rasband, NIH, Bethesda, MD, USA). Plasma membrane lipid raft cluster fluorescence was quantified as the mean fluorescence intensity of plasma membrane areas identified using the software as regions of interest (ROIs). These ROIs were manually selected to exclusively comprise the cell membrane boundaries. The fluorescence intensity was quantified by the sum of the pixel intensities divided by the number of pixels enclosed in the selected area.

\section{Plasma membrane fluidity analysis by electron paramagnetic resonance spectroscopy}

After each drug treatment, plasma membrane fluidity was determined by electron paramagnetic resonance (EPR) spin-labeling spectroscopy according to a previously published protocol (Fridolfsson et al. 2012). Briefly, EPR identifies changes in the spin tropic movement of an unpaired electron. As a spin label, we used 5-doxylstearic acid (5-DSA), which is a derivative of stearic acid with a nitroxyl free radical group located at the fifth carbon, to determine the local fluidity near the polar head groups of the lipid bilayer (Marczak et al. 2006). The final concentration of 5-DSA was $1 \mathrm{mM}$ in a $20 \mu \mathrm{l}$ suspension of INS-1E cells. These cell samples were then placed in a $50 \mu \mathrm{l}$ Magnettech capillary tube and analyzed using a Magnettech MiniScope MS400 benchtop spectrometer (Magnettech, Berlin, Germany). EPR conditions were the following: microwave power, $7 \mathrm{~mW}$; modulation amplitude, $2 \mathrm{G}$; modulation frequency, $100 \mathrm{kHz}$; sweep width, $146.21 \mathrm{G}$ centered at $3357.90 \mathrm{G}$; and scan rate, $7.31 \mathrm{G} / \mathrm{s}$. Each spectrum represents an average of results from ten scans. By analyzing the spectrum of 5-DSA, an order parameter can be calculated from the outer and inner hyperfine splitting $2 \mathrm{~T}_{/ /}$and $2 \mathrm{~T}_{\perp}$ respectively, from which the rotational correlation time of the spin probe and fluid-torigid membrane ratio are derived (Gescheidt 2009).

\section{Statistical analyses}

One-way ANOVA with Tukey's post hoc test was used in the insulin secretion experiments using GGTi, GGPP, and

Published by Bioscientifica Ltd 
GGPP/SIM at $16.7 \mathrm{mM}$ glucose, in the total cholesterol content analyses, in the lipid raft staining mean fluorescence analysis, and in the EPR experiments. Two-way ANOVA followed by Bonferroni's post hoc test was used in all the other insulin secretion assays. Statistical significance was set at $P<0.05$.

\section{Results}

\section{Acute $(2 \mathrm{~h})$ cholesterol biosynthesis inhibition mediated by SIM, but not by ZGA, reduces insulin secretion}

To evaluate the short-term effect of inhibition of cholesterol biosynthesis on GSIS, INS-1E cells were treated for $2 \mathrm{~h}$ with increasing concentrations of SIM. One micromolar SIM treatment decreased insulin secretion only with high levels of glucose (Fig. 1A) without a significant reduction in total cholesterol (Fig. 1B). To evaluate whether this short-term effect of SIM could be due to a reduction in protein isoprenylation, cholesterol biosynthesis was inhibited downstream of farnesyl pyrophosphate by treatment of INS-1E cells for $2 \mathrm{~h}$ with increasing concentrations of ZGA. No effect on GSIS was observed after this treatment (Fig. 1C). A possible toxic effect of SIM can be ruled out because SIM did not affect the cellular viability up to $24 \mathrm{~h}$ of treatment (Supplementary Fig. 1, see section on supplementary data given at the end of this article). In addition, no changes in total insulin content were observed for the two treatments (Supplementary Fig. 2A and B). These results indicate a role for protein isoprenylation in GSIS.

\section{GGPP prevents the acute inhibitory effect of SIM on GSIS}

We further characterized the role of protein isoprenylation as a mechanism in the acute effect, i.e. without changes in total cholesterol, of SIM on GSIS. For that, we investigated the role of the isoprenylation substrate GGPP, as well as of its transferase, in INS-1E cells. When INS-1E cells were treated for $2 \mathrm{~h}$ with the GGTi $(10 \mu \mathrm{M})$, GSIS was impaired to levels similar to those seen after acute treatment with $1 \mathrm{mM}$ SIM. Consistent with these findings, when INS-1E cells were loaded with $20 \mu \mathrm{M}$ GGPP and then challenged with $1 \mu \mathrm{M}$ SIM, the inhibitory effect of SIM was abolished (Fig. 2A). These results further indicate that the acute inhibition of cholesterol biosynthesis impairs GSIS through mechanisms that are dependent on the inhibition of protein geranylgeranylation.

In order to confirm the importance of isoprenylation in GSIS, these treatments were replicated in mouse islets.
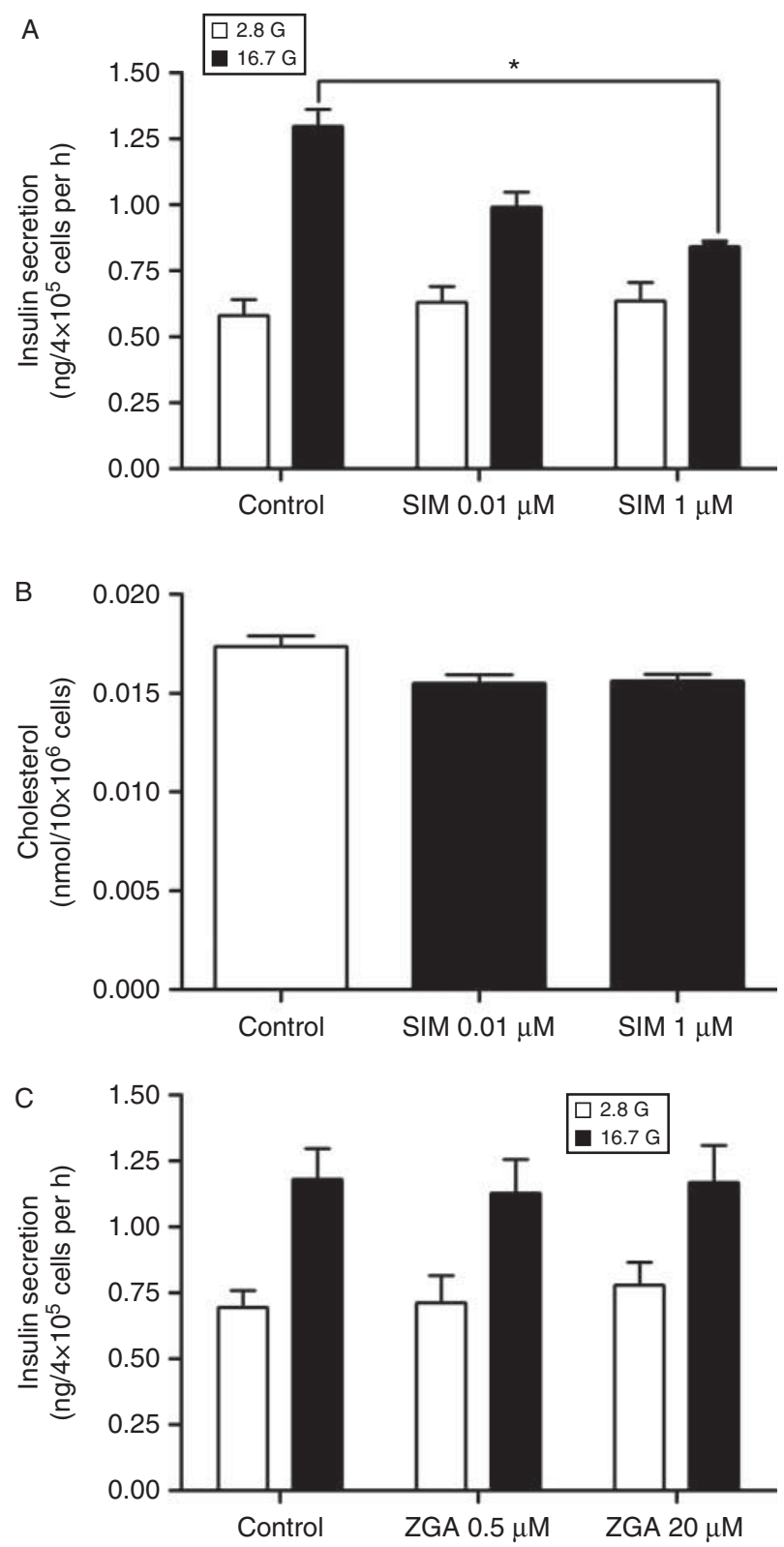

Figure 1

Acute inhibition of glucose-stimulated insulin secretion (GSIS) by simvastatin $(2 \mathrm{~h})$ is not associated with a reduction in cholesterol content. (A) Insulin secretion from INS-1E cells after $2 \mathrm{~h}$ SIM treatment $(n=6)$; (B) SIM $2 \mathrm{~h}$ treatment does not reduce total cellular cholesterol content $(n=4)$. (C) Acute ( 2 h) ZGA treatment does not affect GSIS in INS-1E cells $(n=6)$. $* P<0.05$.

Similarly to the effect observed in INS-1E cells, the acute treatment with SIM and GGTi also inhibited GSIS in mouse islets. This effect was partially prevented by loading with GGPP previously (Fig. 2B). These results indicate that in the intact islet the contribution of other isoprenoid groups is also relevant to GSIS.

Published by Bioscientifica Ltd. 
A

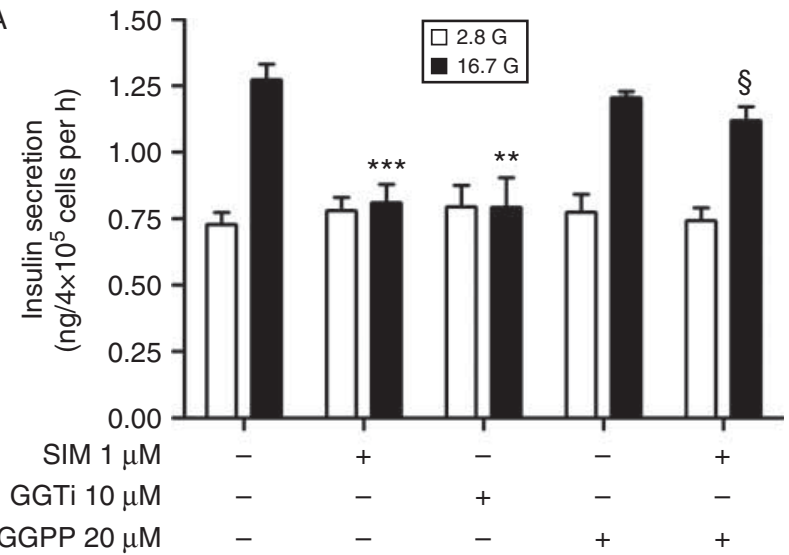

B

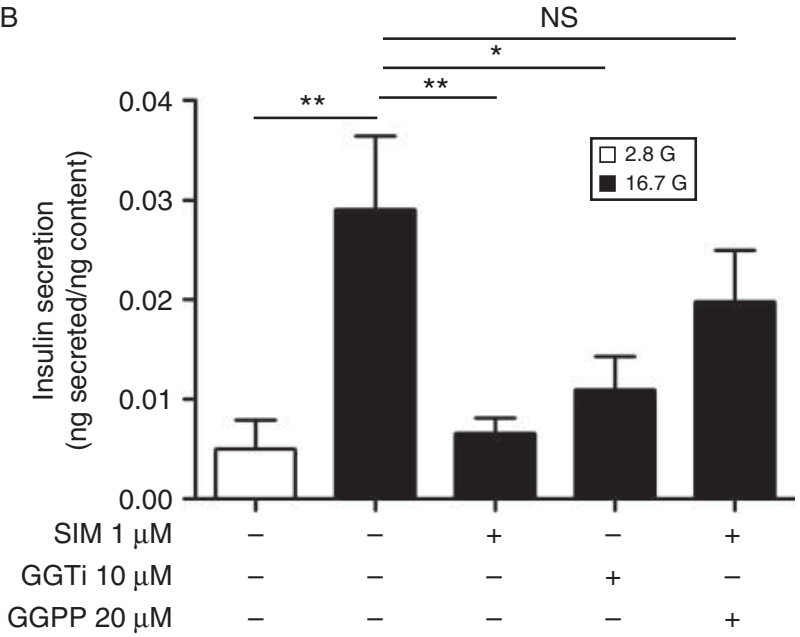

Figure 2

Simvastatin inhibits glucose-stimulated insulin secretion (GSIS) after an acute treatment by inhibiting a geranylgeranyl pyrophosphate-dependent mechanism. (A) Acute inhibition of GSIS by GGTi $(10 \mu \mathrm{M})$ and its prevention in INS-1E cells pre-loaded with GGPP $(20 \mu \mathrm{M})$ after acute SIM treatment $(n=5) . * * P<0.01$ and $* * * P<0.001$ versus control. ${ }^{\S} P<0.05$ versus SIM $1 \mu \mathrm{M}$. (B) Acute inhibition of GSIS by GGTi $(10 \mu \mathrm{M})$ and its amelioration in mouse islets pre-loaded with GGPP $(20 \mu \mathrm{M})$ after acute treatment with $\operatorname{SIM}(n=8)$. $* P<0.05$ and $* * P<0.01$.

\section{Chronic (24 h) inhibition of cholesterol biosynthesis by SIM and ZGA reduces cellular cholesterol content, impairing insulin secretion}

The progression of the inhibition of cholesterol biosynthesis by a long-timer treatment with SIM ( $24 \mathrm{~h})$ did, however, significantly decrease total cholesterol content, as did the positive control MBCD (Fig. 3A). In parallel, GSIS remained inhibited (Fig. 3B). As this effect could be attributed to reductions in both the cellular cholesterol content and protein isoprenylation, we used a method to isolate the effect of final cholesterol production. For that, we used a chronic $24-\mathrm{h}$ ZGA treatment to mimic only the cholesterol-lowering effect of SIM while still preserving isoprenyl groups (Fig. 3C). Similarly to SIM, $20 \mu \mathrm{M}$ ZGA impaired GSIS (Fig. 3D). Mouse pancreatic islets subjected to the same ZGA $(20 \mu \mathrm{M})$ treatment also showed significant reductions in GSIS after $24 \mathrm{~h}$ (Fig. 3E).

\section{Chronic inhibition of cholesterol biosynthesis affects membrane lipid domains and increases plasma membrane fluidity}

To estimate the integrity of membrane cholesterol microdomains after SIM treatment, lipid rafts were stained with fluorescent cholera-B toxin. We observed no differences in the distribution of lipid raft clusters in the plasma membranes of INS-1E cells compared with controls after $2 \mathrm{~h}$ SIM treatment (Fig. 4). In contrast, the 24-h SIM treatment resulted in the dispersion of fluorescent clusters compared with untreated cells (Fig. 4), similar to the effects of cholesterol depletion with M $\beta C D$ (Fig. 4).

The structural changes in the plasma membrane caused by a reduction in cholesterol content were confirmed by EPR experiments that investigated plasma membrane fluidity. Only the 24-h treatment with SIM
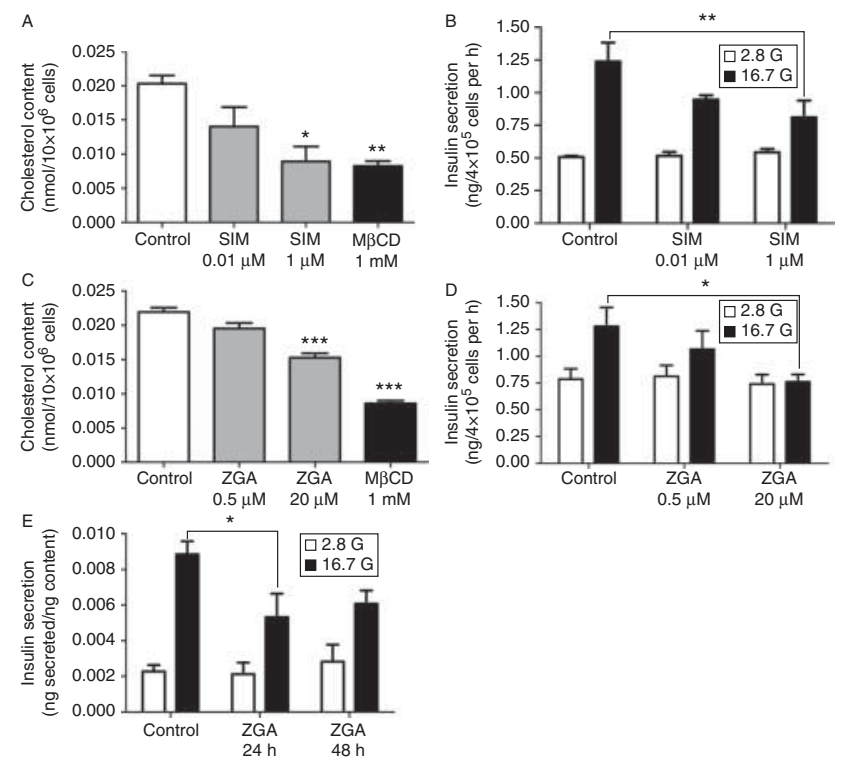

\section{Figure 3}

Chronic (24 h) simvastatin and ZGA treatments reduce glucose-stimulated insulin secretion (GSIS) with concomitant reduction in total cellular cholesterol content. In INS-1E cells the chronic $(24 \mathrm{~h})$ treatment with SIM reduces the total cellular cholesterol content $(A)(n=3)$ with a reduction in GSIS (B) $(n=4)$. In INS-1E cells, the chronic $(24 \mathrm{~h})$ treatment with ZGA reduces cellular cholesterol (C) $(n=3)$ with reduction in GSIS (D) $(n=5)$. In mouse pancreatic islets, the chronic ( 24 and $48 \mathrm{~h}$ ) treatment with ZGA reduces GSIS (E) $(n=4) * P<0.05, * * P<0.01$, and $* * * P<0.001$ versus control. 

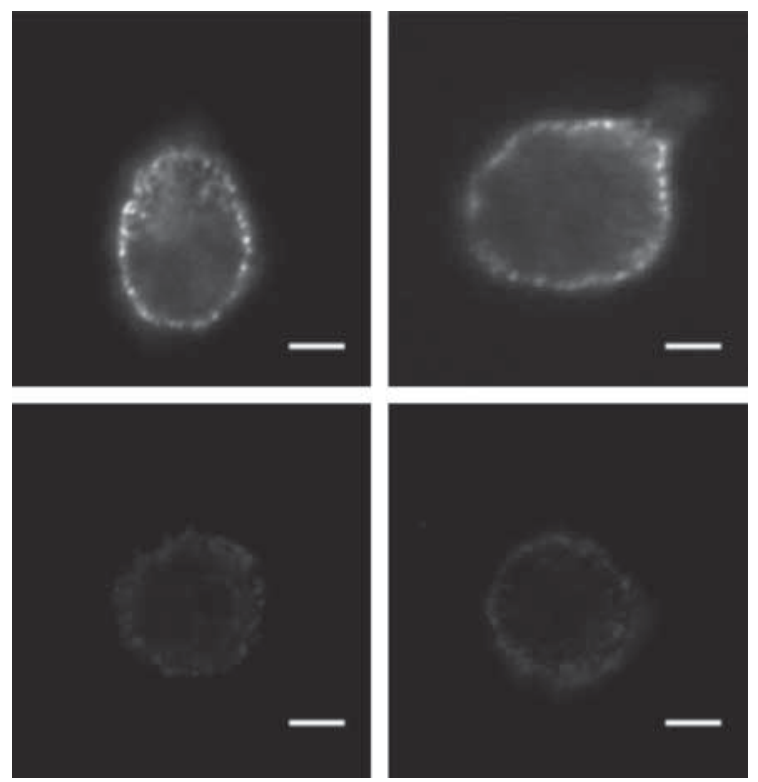

B

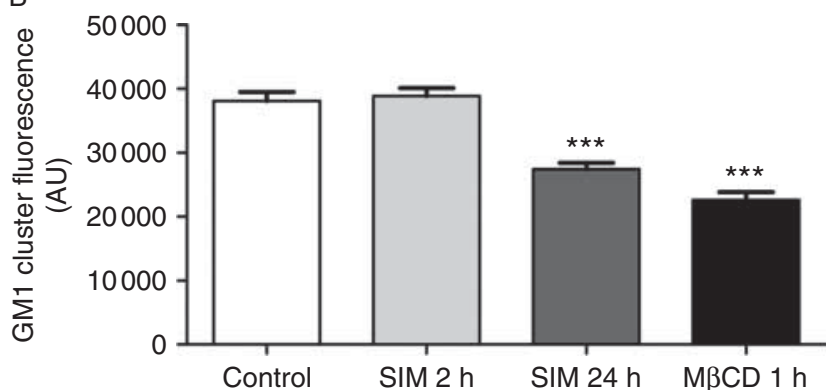

Figure 4

Lipid raft membrane staining is affected by $24 \mathrm{~h}$ treatment with simvastatin, but not by $2 \mathrm{~h}$ treatment. (A) Representative images of lipid rafts in the plasma membranes of INS-1E cells stained with cholera-B toxin. Upper panel (left), lipid raft staining in control (untreated) cells; upper panel (right), lipid raft staining in cells treated with $1 \mu \mathrm{M}$ simvastatin for $2 \mathrm{~h}$; lower panel (left) lipid raft staining in cells treated with $1 \mu \mathrm{M}$ simvastatin for $24 \mathrm{~h}$; lower panel (right), lipid raft staining in cells treated with $1 \mathrm{mM} \mathrm{M} \beta C D$ for $1 \mathrm{~h}$. (B) Mean fluorescence of lipid raft staining represented in (A) (30 ROIs each condition, from three independent experiments). Scale bars: $10 \mu \mathrm{m}$. $* * * P<0.001$ vs control. The arbitrary units (AU) correspond to the sum of the gray values of all pixels in the ROI divided by the number of pixels (ImageJ User Guide, ImageJ/Fiji 1.46).

clearly decreased membrane rigidity (Fig. 5). A shift in the EPR signal to a similar profile to that for cells treated with $\mathrm{M} \beta \mathrm{CD}$ was observed (Fig. 5A). The decrease in the 5-DSA rotational correlation time by treatments with both SIM for $24 \mathrm{~h}$ and $\mathrm{M} \beta \mathrm{CD}$ for $1 \mathrm{~h}$ (Fig. 5B) demonstrated an increase in the rotational degree of freedom of the probe. Moreover, the reduction in cholesterol content was reflected by a decrease in the ratio between rigid and fluid membrane areas (Fig. 5C).

\section{Discussion}

In this study, we show that inhibition of cholesterol biosynthesis results in the impairment of GSIS via acute and chronic effects, which are associated with reduction in protein isoprenylation and disruption of membrane fluidity respectively.

Inhibition of the cholesterol biosynthesis pathway for $2 \mathrm{~h}$ with SIM impairs GSIS (Fig. 1A). However, there was no concomitant change in plasma membrane fluidity (Fig. 5),

A
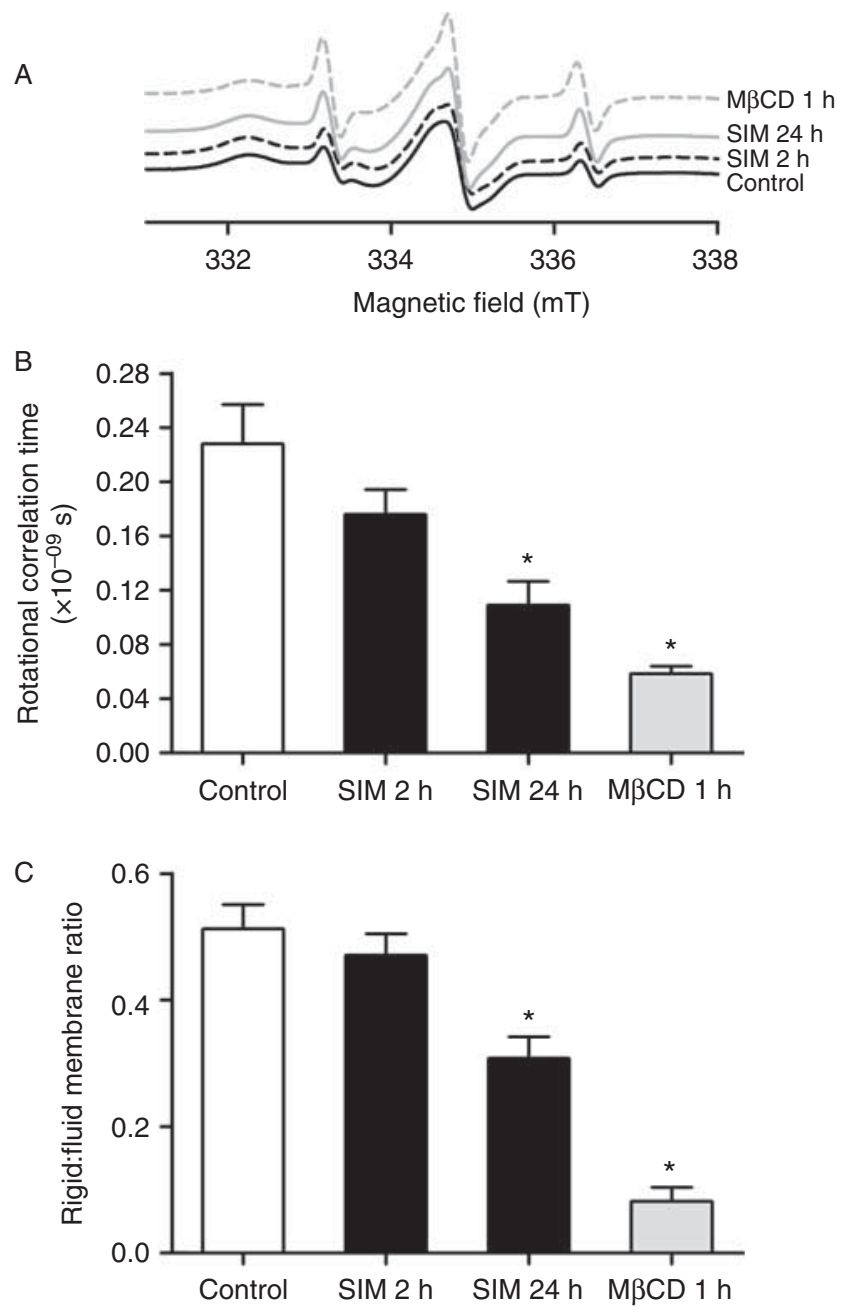

\section{Figure 5}

Chronic 24-h simvastatin treatment increases membrane fluidity in INS-1E cells. (A) Mean traces are shown for two component spectra registered with 5-DSA as a probe to reflect rigid (cholesterol-rich lipid rafts) and fluid membrane microenvironments. Control (continuous black line, $n=8$ ), SIM for $2 \mathrm{~h}$ (dashed black line, $n=8$ ), SIM for $24 \mathrm{~h}$ (continuous gray line, $n=8$ ), and $\mathrm{M} \beta C D$ for $1 \mathrm{~h}$ (dashed gray line, $n=8$ ). (B) The rotational correlation time $\left(T_{\text {corr }}\right)$ of 5-DSA was also calculated to evaluate membrane rigidity close to the hydrophilic surface of the phospholipid bilayer $(n=8)$. (C) Analysis of the two-component spectra by calculating the rigid:fluid ratio of cell membranes $(n=8)$. ${ }^{\star} P<0.05$ vs control.

Published by Bioscientifica Ltd 
in cellular cholesterol content (Fig. 1B), and in membrane lipid microdomain clusters (Fig. 4). In addition, the blockade of the cholesterol pathway downstream of isoprenoid synthesis did not interfere with insulin secretion (Fig. 1C). Moreover, it has been shown in vitro that there is no cholesterol efflux mediated by lipoproteins (Tam et al. 2006, Takeo et al. 2008), and $2 \mathrm{~h}$ seems to be a short time for total cholesterol turnover through its diffusion to the albumin in the culture medium (Fig. 1B). This indicates that the 2-h of treatment with SIM did not cause alterations in the membrane ultrastructure dependent on cholesterol that would affect insulin secretion.

However, it has been proposed that protein isoprenylation is an important factor that contributes to insulin secretion, possibly due to the migration toward the plasma membrane and fusion of the appropriate granule (Kowluru 2008). Isoprenyl intermediates from cholesterol biosynthesis also have a hydrophobic nature. Amongst them, geranylgeranyl presents the highest affinity with lipid bilayers (Silvius \& l'Heureux 1994), the incorporation of isoprenyl intermediates into proteins, such as small GTPases, increases their interaction with membranes.

Geranylgeranylation occurs via the incorporation of GGPP into proteins by a thioester bond to the cysteine of a C-terminal consensus region by geranylgeranyl transferase type 1 , which becomes active at high glucose concentrations (Pechlivanis \& Kuhlmann 2006, Goalstone et al. 2010). In this work, the acute inhibitory effect of SIM on insulin secretion was restricted to the high-glucose-stimulus group (Fig. 1A). This could be mimicked by the GGTi (Fig. 2) and prevented by GGPP loading. This indicates that geranylgeranyl transferase activity is not inhibited by the acute SIM treatment. Moreover, it indicates that increased protein geranylgeranylation, through the activation of geranylgeranyl transferase by glucose, may constitute one of the mechanisms underlying the amplifying pathway of insulin secretion (Nenquin et al. 2004), provided its substrate, GGPP, is available.

Although GGPP loading prevented the inhibitory effect of 2-h treatment with SIM on GSIS (Fig. 2A), we cannot exclude the involvement of other isoprenoid molecules in other cellular process that could affect insulin secretion. This contribution seems to be more evident in pancreatic islets, because GGPP did not fully prevent the effects of $2 \mathrm{~h}$ of SIM treatment (Fig. 2B). In this work, we have not investigated which proteins are involved in the acute effects of the inhibition of the formation of isoprenyl groups in insulin-secreting cells. Further work should address whether decreased geranylgeranylation of proteins, such as RAC1 and CDC42, that actively participate in insulin granule traffic and fusion, respectively (Nevis \& Thurmond 2005, 2006, Kowluru 2011), is involved in the negative effect of the acute SIM treatment on insulin secretion.

The effect of inhibition of cholesterol biosynthesis on insulin secretion seems not to be restricted to impaired protein isoprenylation. The sustained inhibition of cholesterol biosynthesis indicates an additional mechanism for the impairment of insulin secretion, which would be dependent on the cholesterol content.

Treatment with SIM for a longer time ( $24 \mathrm{~h})$ leads to a significant reduction in total cholesterol content (Fig. 3A) and cholesterol membrane organization (Fig. 4). It has been proposed that insulin-secreting cells have active sites organized in functional microdomains of the plasma membrane, whose structures depend on the membrane cholesterol content (Nevis \& Thurmond 2006), and these appear to be lipid rafts (Xia et al. 2004). Inhibition of cholesterol biosynthesis for $24 \mathrm{~h}$ seems to be an enough time for cellular cholesterol turnover in in vitro conditions (Fig. 3A), which was paralleled by a concomitant reduction in GSIS (Fig. 3B). Moreover, the specific blockade of the cholesterol synthesis, i.e. downstream of the isoprenoid synthesis, does interfere with insulin secretion (Fig. 3D and E) concomitant with cholesterol reduction (Fig. 3C). This evidence indicates that changes in cholesterol content per se critically affect insulin secretion and membrane physical properties.

The parallel increase in the plasma membrane fluidity (Fig. 5) may have several functional effects. From a structural perspective, cholesterol and lipids aggregate in membranes occupying less area than they do as separate constituents (Yamamoto et al. 2010). Thus, the finding of a more fluid environment could mean a less packed organization of the membrane. Under these conditions, a higher thermal motion of the phospholipid chains is expected, reducing the probability of formation of cholesterol-based nanostructures. As the hydrophobic transmembrane domains of proteins require particular lipids surrounding the hydrophobic core (Lee 2003), the higher fluidity could cause misplacement of proteins from membrane lipid rafts. In addition, proteins that may be required to be in proximity with each other and that are arranged in lipid rafts that could have their functions compromised because of this membrane randomization.

Thus, it is possible that the impairment of insulin secretion in INS-1E cells after an increase in membrane fluidity due to a reduction in cholesterol would lead to disorganization of membrane microdomains. This effect could cause a loss of the localization to lipid rafts of key proteins for exocytosis, which compromise the secretory machinery and insulin secretion. In order for the granule

Published by Bioscientifica Ltd. 


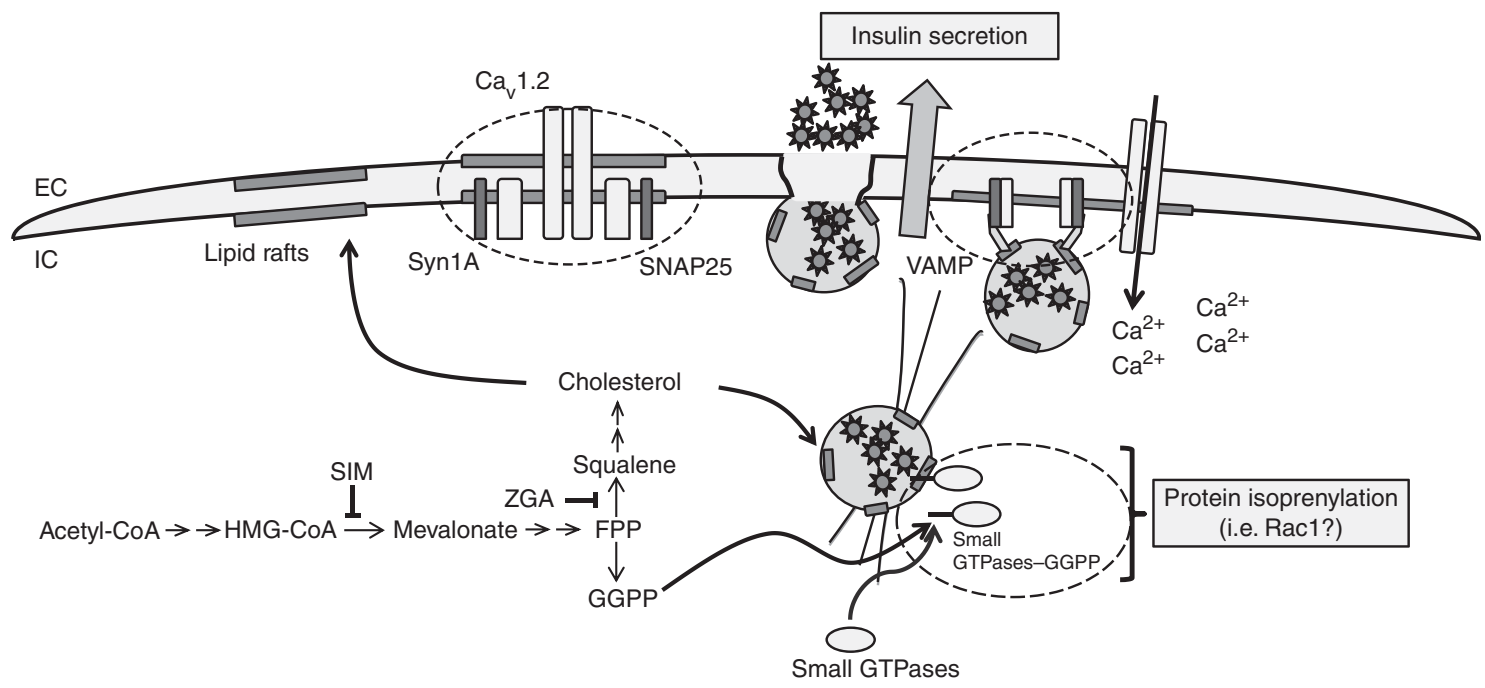

\section{Figure 6}

Schematic representation of glucose-induced insulin secretion with the key points (enclosed by dashed lines) where cholesterol and the intermediates in its biosynthesis would be important. SIM, simvastatin;

fusion to occur, the SNARE complex is arranged into a 'zipper-like' structure that 'closes' after stimulation by $\mathrm{Ca}^{2+}$, providing the force for membrane fusion Jahn \& Scheller 2006, Eliasson et al. 2008, Südhof \& Rothman 2009). In addition, the importance of interactions between SNAREs and ion channels for secretion has been shown (Xia et al. 2004). Thus, the loss of the functional organization of plasma membranes could lead to the loss of this appropriate arrangement.

Thus, we propose that after an acute inhibition of cholesterol synthesis in insulin-secreting cells, the associated impairment of GSIS may be restricted to an effect of reduction in the protein isoprenylation. On the other hand, under longer-duration treatment conditions, the reduction in the secretory capacity is probably mainly due to membrane disarrangement. Even considering the situation in which isoprenoid groups are preserved (i.e. $24 \mathrm{~h}$ ZGA), the observed reduction in GSIS associated with a decrease in cholesterol confirms the critical role of membrane organization in insulin secretion (Fig. 6).

Although we demonstrate herein a critical role of cholesterol biosynthesis as a sterol supplier, the cholesterol uptake (i.e. via LDL receptor) is also an important source of this sterol for islets (Kruit et al. 2010). However, it is not only the cholesterol sources, but also their interplay in the mechanisms responsible for its efflux determines cholesterol homeostasis. The cholesterol transporter ABCA1 appears to be a key regulator of cholesterol efflux, because $\mathrm{ABCA} 1^{-/-}$mouse islets presented high
ZGA, zaragozic acid; GGPP, geranylgeranyl pyrophosphate; FPP, farnesyl pyrophosphate; Syn $1 \mathrm{~A}$, syntaxin $1 \mathrm{~A}$.

cholesterol content with a consequent disruption of GSIS (Kruit et al. 2010, 2011). This negative effect on $\beta$-cell function due to accumulation of cholesterol has also been shown in the overactivation of its sources. SREBP2 regulates the expression of HMG-CoA reductase and LDL receptor, and its overexpression increases cholesterol content, compromising islet morphology and GSIS in mouse islets (Ishikawa et al. 2008).

Thus, not only cholesterol reduction but also a dramatic increase in cholesterol content has been shown to reduce insulin secretion (Kruit et al. 2011, Souza et al. 2013). Taken together, those findings and ours indicate that a critical concentration of cellular/membrane cholesterol content is required for adequate secretion of insulin.

\section{Supplementary data}

This is linked to the online version of the paper at http://dx.doi.org/10.1530/ JOE-14-0348.

\section{Declaration of interest}

The authors declare that there is no conflict of interest that could be perceived as prejudicing the impartiality of the research reported.

\section{Funding}

This work was supported by the Conselho Nacional de Desenvolvimento Científico e Tecnológico, (CNPq) (202011/2011-9), Fundação de Amparo à Pesquisa do Estado de São Paulo, (FAPESP) (2009/50444-7), Coordenação de Aperfeiçoamento de Pessoal de Nível Superior, (CAPES), Brazil, the National

Published by Bioscientifica Ltd 
Institutes of Health USA HL091071 (H H P) and HL107200 (H H P), and Veterans Affairs Merit BX001963 (H H P).

\section{Author contribution statement}

J P Z-H carried out experimental design, experimental procedures, data analysis, and paper writing. E R carried out experimental design, data analysis, and paper writing. A K carried out experimental procedures (cell culture and EPR) and paper reviewing. S S A and A M K performed EPR data analysis. H H P was involved in paper writing and reviewing. F A carried out experimental design, paper writing, and reviewing.

\section{Acknowledgements}

The authors thank Prof. Pierre Maechler (Université de Genève, Switzerland) for providing the INS-1E cells and Dr Patrick Gilon (Université Catholique de Louvain, Belgium) for critical comments on the manuscript.

\section{References}

Eliasson L, Abdulkader F, Braun M, Galvanovskis J, Hoppa MB \& Rorsman P 2008 Novel aspects of the molecular mechanisms controlling insulin secretion. Journal of Pathology 586 3313-3324.

Fridolfsson HN, Kawaraguchi Y, Ali SS, Panneerselvam M, Niesman IR, Finley JC, Kellerhals SE, Migita MY, Okada H, Moreno AL et al. 2012 Mitochondria-localized caveolin in adaptation to cellular stress and injury. FASEB Journal 26 4637-4649. (doi:10.1096/fj.12-215798)

Fukuda M 2005 Versatile role of Rab27 in membrane trafficking: focus on the Rab27 effector families. Journal of Biochemistry 137 9-16. (doi:10.1093/jb/mvi002)

Gescheidt G 2009 Electron paramagnetic resonance spectroscopy in the liquid phase. In Electron Paramagnetic Resonance, A Practitioner's Toolkit, edn 1, pp 116-130. Eds M Brustolon \& E Giamello. Hoboken: John Wiley \& Sons, Inc.

Goalstone M, Kamath V \& Kowluru A 2010 Glucose activates prenyltransferases in pancreatic islet $\beta$ cells. Biochemical and Biophysical Research Communications 391 895-898. (doi:10.1016/ j.bbrc.2009.11.159)

Henquin JC 2000 Triggering and amplifying pathways of regulation of insulin secretion by glucose. Diabetes 49 1751-1760. (doi:10.2337/ diabetes.49.11.1751)

Ishikawa M, Iwasaki Y, Yatoh S, Kato T, Kumadaki S, Inoue N, Yamamoto T, Matsuzaka T, Nakagawa Y, Yahagi N et al. 2008 Cholesterol accumulation and diabetes in pancreatic $\beta$-cell-specific SREB- 2 transgenic mice: a new model for lipotoxicity. Journal of Lipid Research 49 2524-2534. (doi:10.1194/jlr.M800238-JLR200)

Jahn R \& Scheller RH 2006 SNAREs-engines for membrane fusion. Nature Reviews. Molecular Cell Biology 7 631-643. (doi:10.1038/nrm2002)

Kowluru A 2008 Protein prenylation in glucose-induced insulin secretion from the pancreatic islet $\beta$ cell: a perspective. Journal of Cellular and Molecular Medicine 12 164-173. (doi:10.1111/j.1582-4934.2007.00168.x)

Kowluru A 2011 Friendly, and not so friendly, roles for Rac1 in islet $\beta$-cell function: lessons learnt from pharmacological and molecular biological approaches. Biochemical Pharmacology 81 965-975. (doi:10.1016/j.bcp.2011.01.013)

Kruit JK, Kremer PH, Dai L, Tang R, Ruddle P, de Haan W, Brunham LR, Verchere CB \& Hayden MR 2010 Cholesterol efflux via ATP-binding cassette transporter A1 (ABCA1) and cholesterol uptake via LDL receptor influences cholesterol-induced impairment of $\beta$ cell function in mice. Diabetologia 53 1110-1119. (doi:10.1007/s00125-010-1691-2)

Kruit JK, Wijesekara N, Fox JE, Dai XQ, Brunham JR, Searle GJ, Morgan GP, Costin AJ, Tang R, Bhattacharjee A et al. 2011 Islet cholesterol accumulation due to loss of ABCA1 leads to impaired exocytosis of insulin granules. Diabetes 60 3186-3196. (doi:10.2337/db11-0081)

Lacy PE \& Kostianovsky M 1967 Method for the isolation of intact islets of Langerhans from the rat pancreas. Diabetes 16 35-39. (doi:10.2337/ diab.16.1.35)

Lee AG 2003 Lipid-protein interactions in biological membranes: a structural perspective. Biochimica et Biophysica Acta 1612 1-40. (doi:10.1016/S0005-2736(03)00056-7)

Li J, Luo R, Kowluru A \& Li G 2004 Novel regulation by Rac1 and glucoseand forskolin-induced insulin secretion in INS-1 $\beta$ cells. American Journal of Physiology. Endocrinology and Metabolism 286 E818-E827. (doi:10.1152/ajpendo.00307.2003)

Linetti A, Fratangeli A, Taverna E, Valnegri P, Francolini M, Cappello V, Matteoli M, Passafaro M \& Rosa P 2010 Cholesterol reduction impairs exocytosis of synaptic vesicles. Journal of Cell Science 123 595-605. (doi:10.1242/jcs.060681)

Marczak A, Kowalczyk A, Wrzesien-Kus A, Robak T \& Jozwiak Z 2006 Interaction of doxorubicin and idarubicin with red blood cells from acute myeloid leukaemia patients. Cell Biology International 30 127-132. (doi:10.1016/j.cellbi.2005.09.001)

van Meer G, Voelker DR \& Feigenson GW 2008 Membrane lipids: where they are and how they behave. Nature Reviews. Molecular Cell Biology 9 112-124. (doi:10.1038/nrm2330)

Merglen A, Theander S, Rubi B, Chaffard G, Wollheim CB \& Maechler P 2004 Glucose sensitivity and metabolism-secretion coupling studied during two-year continuous culture in INS-1E insulinoma cells. Endocrinology 145 667-678. (doi:10.1210/en.2003-1099)

Nenquin M, Szollosi A, Aguilar-Bryan L, Bryan J \& Henquin JC 2004 Both triggering and amplifying pathways contribute to fuel-induced insulin secretion in the absence of sulfonylurea receptor- 1 in pancreatic $\beta$-cells. Journal of Biological Chemistry 279 32316-32324. (doi:10.1074/jbc. M402076200)

Nevis AK \& Thurmond DC 2005 A direct interaction between Cdd42 and vesicle-associated membrane protein 2 regulates SNARE-dependent insulin exocytosis. Journal of Biological Chemistry 280 1944-1952. (doi:10.1074/jbc.M409528200)

Nevis AK \& Thurmond DC 2006 Caveolin-1 functions as a novel Cdc42 guanine nucleotide dissociation inhibitor in pancreatic $\beta$ cells. Journal of Biological Chemistry 281 18961-18972. (doi:10.1074/jbc. M603604200)

Parpal S, Karlsson M, Thorn H \& Stralfors P 2001 Cholesterol depletion disrupts caveolae and insulin receptor signaling for metabolic control via insulin receptor substrate-1, but not for mitogen-activated protein kinase control. Journal of Biological Chemistry 276 9670-9678. (doi:10.1074/jbc.M007454200)

Pechlivanis M \& Kuhlmann J 2006 Hydrophobic modifications of Ras proteins by isoprenoid groups and fatty acids - more than just membrane anchoring. Biochimica et Biophysica Acta 1764 1914-1931. (doi:10.1016/j.bbapap.2006.09.017)

Pike L 2003 Lipid rafts: bringing order to chaos. Journal of Lipid Research 44 655-667. (doi:10.1194/jlr.R200021-JLR200)

Silvius JR \& l'Heureux F 1994 Fluorometric evaluation of the affinities of isoprenylated peptides for lipid bilayers. Biochemistry 33 3014-3022. (doi:10.1021/bi00176a034)

Singer SJ \& Nicolson GL 1972 The fluid mosaic model of the structure of cell membranes. Science 175 720-731. (doi:10.1126/science.175.4023.720)

Souza JC, Vanzela EC, Ribeiro RA, Rezende LF, de Oliveira CA, Carneiro EM, Oliveira HC \& Boschero AC 2013 Cholesterol reduction ameliorates glucose-induced calcium handling and insulin secretion in islets from low-density lipoprotein receptor knockout mice. Biochimica et Biophysica Acta 1831 769-775. (doi:10.1016/j.bbalip.2012.12.013)

Südhof TC \& Rothman JE 2009 Membrane fusion: grappling with SNARE and SM proteins. Science 323 474-477. (doi:10.1126/science.1161748)

Takeo T, Hoshii T, Kondo Y, Toyodome H, Arima H, Yamamura K, Irie T \& Nakagata N 2008 Methyl- $\beta$-cyclodextrin improves fertilizing ability of C57BL6 mouse sperm after freezing and thawing by facilitating 
cholesterol efflux from the cells. Biology of Reproduction 78 546-551. (doi:10.1095/biolreprod.107.065359)

Tam SP, Mok L, Chimini G, Vasa M \& Deeley RG 2006 ABCA1 mediates highaffinity uptake of 25-hydroxycholesterol by membrane vesicles and rapid efflux of oxysterol by intact cells. American Journal of Physiology. Cell Physiology 291 C490-C502. (doi:10.1152/ajpcell.00055.2006)

Vikman J, Jimenez-Felström J, Nyman P, Thelin J \& Eliasson L 2009 Insulin secretion is highly sensitive to desorption of plasma membrane cholesterol. FASEB Journal 23 58-67. (doi:10.1096/fj.08-105734)

Wang Z \& Thurmond D 2009 Mechanisms of biphasic insulin-granule exocytosis - roles of the cytoskeleton, small GTPases and SNARE proteins. Journal of Cell Science 122 893-903. (doi:10.1242/jcs.034355)

Xia F, Gao X, Kwan E, Lam PP, Chan L, Sy K, Sheu L, Wheeler MB, Gaisano HY $\&$ Tsushima RG 2004 Disruption of pancreatic $\beta$-cell lipid rafts modifies
Kv2.1 channel gating and insulin exocytosis. Journal of Biological Chemistry 279 24685-24691. (doi:10.1074/jbc.M314314200)

Xia F, Xie L, Mihic A, Gao X, Chen Y, Gaisano HY \& Tsushima RG 2008 Inhibition of cholesterol biosynthesis impairs insulin secretion and voltage-gated calcium channel function in pancreatic $\beta$-cells. Endocrinology 149 5136-5145. (doi:10.1210/en.2008-0161)

Yamamoto T, Brewester R \& Safran SA 2010 Chain ordering of hybrid lipids can stabilize domains in saturated/hybrid/cholesterol lipid membranes. Europhysics Letters 91 28002. (doi:10.1209/0295-5075/ 91/28002)

van Zanten TS, Gómez J, Manzo C, Cambi A, Buceta J, Reigada R \& Garcia-Parajo MF 2010 Direct mapping of nanoscale compositional connectivity on intact cell membranes. PNAS 107 15437-15442. (doi:10.1073/pnas.1003876107)

Received in final form 16 October 2014

Accepted 28 October 2014

Accepted Preprint published online 28 October 2014
C 2015 Society for Endocrinology Printed in Great Britain
Published by Bioscientifica Ltd. 